\title{
Prevalence of hyperuricemia in Chitwan District of Nepal
}

\author{
S. Kumar ${ }^{1}$, A.R. Singh², R. Takhelmayum ${ }^{3}$, P. Shrestha ${ }^{4}$, J. N. Sinha ${ }^{5}$ \\ ${ }^{1,3}$ Lecturer, ${ }^{2}$ Asst. Prof, ${ }^{4}$ Lab in charge, ${ }^{5}$ Prof \& HOD of Biochemistry, College of Medical Sciences and Teaching Hospital, \\ Bharatpur, Nepal.
}

\begin{abstract}
The prevalence of hyperuricemia has been increasing in both developed and developing countries. The purpose of present study was to know the prevalence of hyperuricemia in the population of Chitwan district as well as to compare the prevalence of hyperuricemia between Mongolian and non-Mongolian races of Chitwan district, who had attended the College of Medical Sciences and Teaching Hospital, Bharatpur, Nepal during the period of January 1999 to December 2003. In this study 3794 subjects were investigated for serum uric acid level (SUA). Hyperuricemia is defined as SUA more than $7 \mathrm{mg} / \mathrm{dl}$ for males and menopausal women and $6 \mathrm{mg} / \mathrm{dl}$ for pre-menopausal females. SUA was estimated by Caraway method in digital colorimeter. Overall prevalence was $21.42 \%$; the condition was more common in men than women ( $26.78 \%$ vs. $16.82 \%$; $\mathrm{p}<0.001)$. The prevalence was higher in Mongolian than non Mongolian both in males and females (24.50\% Vs $21.06 \%$; $>0.05)$.
\end{abstract}

Key words: Hyperuricemia, SUA, digital colorimeter

\section{Introduction}

Uric acid is the end product of purine metabolism in human beings and in primates. Elevated level of uric acid is directly linked with gout but also associated with risk of hypertension, cardiovascular disease and type 2 Diabetes mellitus ${ }^{1,2}$.

Hyperuricemia may be presented asymptomatically, or manifested in gouty arthritis, uric acid nephropathy, and nephrolithiasis ${ }^{3}$.

Hyperuricemia is diagnosed in $5-30 \%$ of the general population. Although the prevalence is higher among some ethnic groups, it appears to be increasing both in developing and developed countries ${ }^{4}$. The

Correspondence: Dr. Sushil Kumar

E-mail: kumarsshl@yahoo.com

prevalence of hyperuricemia in China in 1980 was reported $1.4 \%$ in men and $1.3 \%$ in women. In 1998, in China, the prevalence of hyperuricemia was $14.2 \%$ in men and $7.11 \%$ in women ${ }^{5}$. Serum uric acid concentration increases with age and further increases after menopausal in women ${ }^{6}$. The prevalence of hyperuricemia is also strongly associated with economical development and life style factors ${ }^{7}$.

Chitwan district is one of the developing districts of Nepal, located in the central region of Nepal and is well connected with hills and Terai areas and has mixed type of populations broadly divided into Mongolian and non Mongolian. The Rais, Limbus, Tamangs, Magars, Sunwars, Jirels, Gurungs, Thakalis, and Chepangs are considered as Mongolian race (Tibeto- 
S. Kumar et al, Prevalence of hyperuricemia in Chitwan District of Nepal

Burman derivatives) found living in the middle hills. Each Mongolian has own distinct social and cultural patterns and specific surname. The Dun valleys and the lowland Terai are inhabited by non- Mongolian such as the Brahmins, Rajputs, Tharus, Danwars, Majhis, Darais, Rajbansis, Statars, Dhimals and Dhangars.

Mostly they are migrated from India and adjacent parts. Therefore social and cultural patterns are different in Mongol and non Mongol people ${ }^{8}$.

Table 1: Showing distribution of caste/ ethnicity of Chitwan district?

\begin{tabular}{ll}
\hline Caste/ethnic & Population in \% \\
\hline Chhetri & $\mathbf{1 0 . 9 5}$ \\
Brahaman (hills) & $\mathbf{2 9 . 3 1}$ \\
Magar & $\mathbf{4 . 1 6}$ \\
Tharu & $\mathbf{1 2 . 7 4}$ \\
Tamang & $\mathbf{7 . 3 6}$ \\
Newar & $\mathbf{5 . 4 3}$ \\
Muslim & $\mathbf{0 . 7 7}$ \\
Kami & $\mathbf{4 . 4 5}$ \\
Yadav & $\mathbf{0 . 1 4}$ \\
Rai (Kirant) & $\mathbf{0 . 6 9}$ \\
Gurung & $\mathbf{6 . 7 3}$ \\
Limbu & $\mathbf{0 . 0 4}$ \\
Damai/dhobi & $\mathbf{2 . 2 4}$ \\
Chepang & $\mathbf{4 . 5 0}$ \\
Darai & $\mathbf{1 . 5 3}$ \\
Kumar & $\mathbf{1 . 6 0}$ \\
Sarkki & $\mathbf{1 . 1 6}$ \\
Others & $\mathbf{1 7 . 8 0}$ \\
\hline
\end{tabular}

Up to now, there is no study on the prevalence of hyperuricemia in the Chitwan district. The present study was conducted to estimate the prevalence of hyperuricemia in Mongol and non Mongol people among the men and women of this district who had come to the College of Medical Sciences and Teaching Hospital, Bharatpur. This study will help us to know about demographic pattern of hyperuricemia and also about the group that will have more chance to develop gout and other related complications.

\section{Materials and methods}

We conducted retrospective study of 3794 outpatients for investigation of SUA level in Biochemistry Department, College of Medical Sciences and Teaching Hospital, Bharatpur, Nepal from January 1999 to December 2003.

Feedback of race and menstrual history of the patients were taken from personal and family history mentioned on the patient's case history reports. Case reports not showing clear cut about ethnicity and other personal history had not been included in our study.

Patients were categorized into males and females, then Mongol and non Mongol. Females were further allocated into menopausal and non menopausal.

Blood sample of selected patients were withdrawn under supervision of Biochemistry department. The estimation of SUA had been done by Caraway's method in digital colorimeter (Systronic).

We defined subjects as hyperuricemic if their serum uric acid concentration was $>7.0 \mathrm{mg} / \mathrm{dl}$ in men and in menopausal women or $>6.0 \mathrm{gm} / \mathrm{dl}$ in pre menopausal women ${ }^{10}$.

Obtained data was fed into MS excel and analyzed, then percentage was deducted and $p$ value was obtained by using Chi-square test. 
Journal of college of Medical Sciences-Nepal, 2010, Vol.6, No-2

\section{Results}

Table No. 2: Showing prevalence of hyperuricemia

\begin{tabular}{|c|c|c|c|}
\hline \multirow[t]{2}{*}{ Sex } & \multicolumn{2}{|c|}{ No. of pts. With SUA } & \multirow[t]{2}{*}{ Prevalence $\quad(\%)$} \\
\hline & Normal & Elevated & \\
\hline Male & 1285 & 470 & 26.78 \\
\hline Female & 1696 & 343 & 16.82 \\
\hline Total $=3794$ & 2981 & 813 & 21.42 \\
\hline
\end{tabular}

Overall, the prevalence of Hyperuricemia was found $21.42 \%$. Hyperuricemia was more frequent in men than women $(26.78 \%$ Vs $16.82 \%)$ ( $<<0.001)$.

Table No. 3: Showing the prevalence of Hyperuricemia and average serum uric acid level race-wise.

The prevalence of Hyperuricemia was $24.50 \%$ in Mon common in Mongol, but statistically not significant ( $\mathrm{p}$ $1.27 \mathrm{mg} / \mathrm{dl}$.

Table No. 4: Proportions of hyperuricemia in differen 
S. Kumar et al, Prevalence of hyperuricemia in Chitwan District of Nepal

Serum uric acid value in men was noted $8.16 \pm 1.10 \mathrm{mg} / \mathrm{dl}$.

Increasing trend of SUA with age was observed. Highest SUA was seen in 41-60 years group in Mongol people $(9.02 \mathrm{mg} / \mathrm{dl})$. Maximum cases of hyperuricemia were observed in 21-40 years age group. No hyperuricemic case was reported in $>20$ years age group in Mongol male. There was significant difference ( $p$ value $<0.0001$ ) between the age groups and hyperuricemia in male.

Table No. 5: Proportions of hyperuricemia in different age groups (female)

Maximum cases of hyperuricemia were observed in 2 $7.33 \pm 1.34 \mathrm{mg} / \mathrm{dl}$. Highest elevation of SUA was obser $(9.46 \mathrm{mg} / \mathrm{dl}$ in Mongol as against $8.78 \mathrm{mg} / \mathrm{dl}$ in non Mong in Mongol female. There is significant difference ( $\mathrm{p}$ valu female.

\section{Discussion}

Among the subjects investigated for SUA, 21.42\% were diagnosed to have hyperuricemia, which showed slightly higher than estimates reported for several other populations. For example, Al-Arfaz and colleagues found that the prevalence of Hyperuricemia was $8.4 \%$ among Saudi men and women ${ }^{11}$; and also study done by Vitool Lohsoonthorn et al on Thai people showed the prevalence was $10.6 \%{ }^{12}$. However, the prevalence

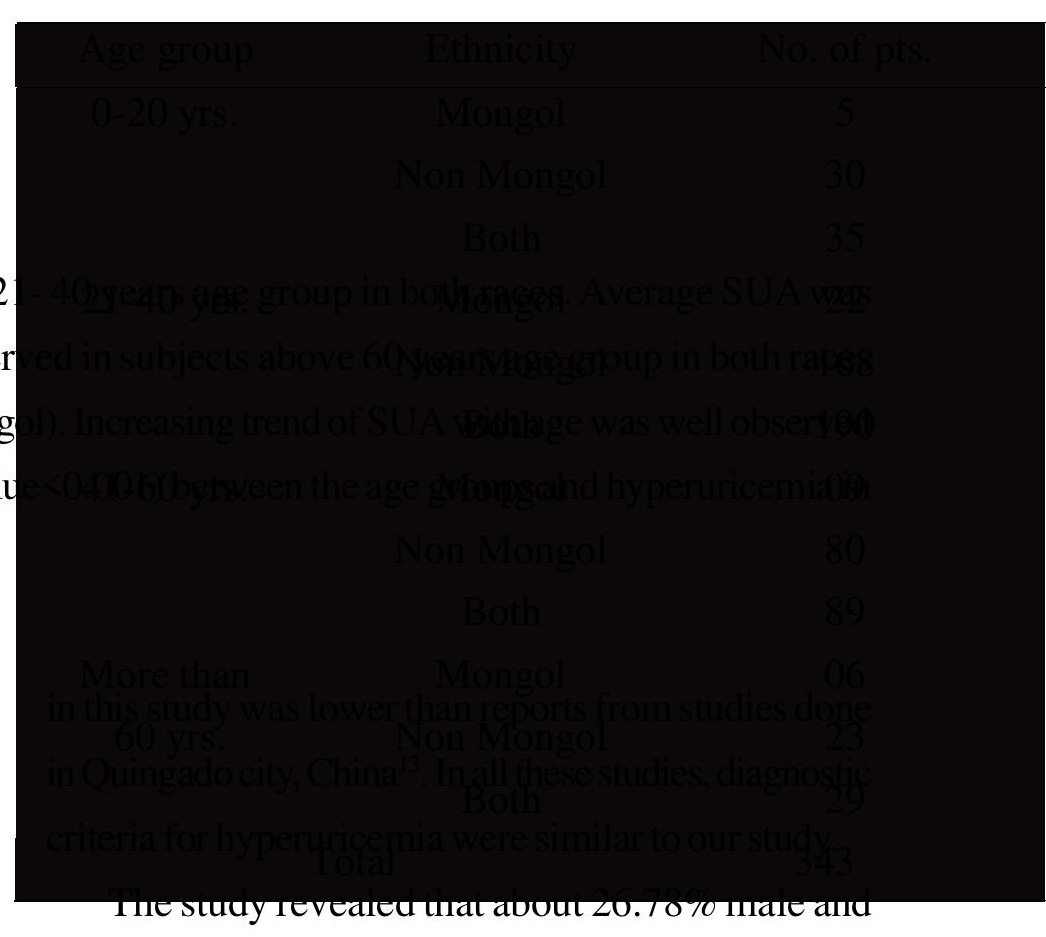

$16.82 \%$ female were hyperuricemic. Other reports, like done by the Nutrition and Health Survey in Taiwan revealed about $26 \%$ of adult male and $17 \%$ of adult female had elevated uric acid level ${ }^{12}$. 
One of the important aspects of our study was to compare the prevalence of hyperuricemia between Mongol and Non Mongol people. In our study, the estimated prevalence of hyperuricemia was found to be statistically non-significantly high in Mongol subjects $(24.50 \%$ Vs $21.06 \%)(p>0.05)$. It was also seen that SUA level was more elevated in Mongol people than Non Mongol $(8.20 \pm 1.59 \mathrm{mg} / \mathrm{dl}$ Vs $7.75 \pm 1.21$ $\mathrm{mg} / \mathrm{dl}$ respectively; $\mathrm{p}<0.01)$. It might be due to Mongol and Non Mongol people of Chitwan living together for long time; so culture, dietary habits and customs would have been adapted to each other. Therefore no clear cut demarcation can be made in view of SUA level.

Serum uric acid level was noted high in male than female $(8.16 \pm 1.10 \mathrm{Vs} 7.33 \pm 1.34$ respectively; $\mathrm{p}<$ 0.005), may be due to the different hormonal status, especially estrogen ${ }^{14,15}$. Menopausal women showed SUA level $8.38 \pm 1.79 \mathrm{mg} / \mathrm{dl}$ (average age$56.60 \pm 9.25$ years) than premenopausal $6.92 \pm 0.78 \mathrm{mg}$ / $\mathrm{dl}$ (mean age-31.17 \pm 7.89 years). This supported that the renal excretion of uric acid is increased by estrogen ${ }^{16}$.

Age appears to be an important risk factor to raise serum uric acid level ${ }^{17}$. Before 20 years of age, prevalence was relatively low $(4.89 \%, 10.20 \%$; male, female respectively). Increasing trend of serum uric acid level with age was observed in male of both races. Maximum cases of hyperuricemia were seen in 2140 years age group $(41.39 \%$ in men \& $55.39 \%$ in women). Similar patterns of increased proportions of hyperuricemia with increasing age have been documented by several other investigators ${ }^{12,18}$.

This study is a hospital record based study, therefore does not simulate the occurrence in community.
Sometimes we cannot get complete records of patients, which could have been useful to give important information for the patients.

\section{Conclusion}

The prevalence of hyperuricemia in this multiethnic, multicultural Chitwan district of Nepal is high. Prevalence is more amongst the Mongols than nonMongols, with males showing higher percentage in both groups. It is alarming, young adults (21-40 years) account for most of the cases. This might be due to change in living style and dietary habits of the people. However, the consumption of more purine rich diet or some other obscure reason is yet to be cleared.

This age group is the work force of the nation and on which economy of the community depends. It has also been reported that hyperuricemia can lead to many other complications such as gouty arthritis, nephrolithiasis, and renal pathology etc ${ }^{3}$. That will further affect the economy of the community. So knowledge about hyperuricemia needs to be developed amongst the people and a healthier living standard should be acquired and extensive community based study is recommended so that appropriate intervention could be started earlier.

\section{Acknowledgement}

We thank to Mr. D. K. Singh and Mr. K. P. Mandal, Senior laboratory technicians who had helped us to collect the data during course of the study. We are also grateful to Mr. N. Manandhar, Assistant professor in community medicine of College of Medical Sciences for his help in statistical analysis. 